\section{Conclusions}

In many normal persons changes in the pulse, from diminution to complete obliteration, can be brought about by changes in the position of the shoulder girdle produced by movements of the arm, and in some, throwing back the shoulder on one side will obliterate the pulse on the opposite side. Probably no one mechanism is responsible in all these cases. Man's upright position, the shape of the upper thoracic opening as determined by the costal arrangement and the form and development of the shoulder girdle and its associated muscles are the chief factors involved.

The clinical features of the syndrome of the upper thoracic opening are either neural or vascular in type. The clavicle only rarely plays a part in their production and costo-clavicular compression may be associated with local damage to the subclavian artery.

Vascular changes with pain in cases of the upper thoracic syndrome call for an exploratory operation to free the artery and the lowest trunk of the brachial plexus from compression. Anterior scalenotomy alone will not suffice in most of these cases; the deep relationships of the artery and the brachial plexus must be examined and the other limb of the vice, if present in the form of a rib, a band or tendinous fibres of the scalenus medius must be divided as well.

\section{Summary}

An explanation is given of why the syndrome of the upper thoracic opening has no counterpart in the lower limb.

The effect of arm and shoulder girdle movements on the pulse is discussed. Costo-clavicular compression is shown to be comparatively rare and when it occurs may lead to vascular changes consequent upon damage to the subclavian artery. The principles of operation for the relief of these syndromes are stated.

\section{BIBLIOGRAPHY}

EDEN, K. C. (1939), Brit. F. Surg., 27, 111 .

FALCONER, M. A., and WEDDËLL, G. (1943), Lancet, ii, 539. LE VAY, A. D. (19+5), Ibid., i1, 164.

LEWIS, T., and PICKERING, G. (1934), Clinical Sci., I, 354.

MURPHY, J. B. (11006), Surg. Gyn. Obst., 3, 514

ROGERS, LAMBERT' (1937), Med. Annual., 55, 94

ROGERS, LAMEERT (1938), Ibid., 56, 92.

ROGERS, LAMEERT (r940), Ibid., 58, 93.

ROGERS, LAMBERT (194I), Ibid., 59, 67.

ROGERS, LAMBERT (r94I), Rev. Cirurg. $B$. Aires, 20, $54 \mathrm{I}$.

ROGERS, LAMBERT (1944), R.N. Medical Bull., 8, 18 .

ROGERS, LAMBERT (1945), Ibid., 63, 283.

ROGERS, LAMBERT, and ALDIS, ARNOLD S. (1947), Brit. Med.' $\mathcal{H}$., $\mathbf{i}, \mathbf{8 2 1}$.

ROGERS, LAMBERT (1948), Med. Annual, 65, 66.

ROGERS, LAMBERT (1949), Brit. Med. F., ii, 956.

ROGERS, LAMBERT (1950), Med. Annuai, 68, 60.

ROGERS, LAMBERT (195I), Brit. Surg. Practice, 3, Butterworth

STAMMERS, F. A. R. (1050), Lancet, i, 603 .

TELFORD, E. D., and STOPFORD, J. S. B. (1930), Brit. $\mathcal{F}$.

Surg., 18, 560.
TELFORD, E. D., and MOTTERSHEAD, S. (1947), Brit. med: Y., $i, 325$.

TODD̈, W. (1911), fourn. Anat. and Physiol., 45, 293.

TODD, W. (1913), Lancet, i, 1371 .

TODD, W. (1913), Fourn. Anat. and Physiol., 47, 250.

\title{
it \\ BASIC MECHANISMS OF ALLERGIC REACTIONS
}

\author{
By J. PePys, M.R.C.P.(Lond.), M.R.C.P.Ed. \\ From the Dept. of Pathology, Guy's Hospital Medical School and Royal National Throat, Nose and Ear Hospital
}

\section{Introduction}

The general integration into everyday medical thought of advances in fundamental knowlege in medical science is often delayed until it has become imperative in order to enhance precision of diagnosis and treatment. The role of allergic reactions has clearly reached this stage and their basic mechanisms will be discussed within the limitations of our present knowledge in which gaps bridged by new developments remain to be filled in later. The term ' allergy' has lost some of its precision and a survey of its origin will help to make its meaning clearer. Arising out of the fascinating and important study of immunity towards the end of the last century came v. Behring's production of diphtheria anti-toxic serum derived from horses. Its extensive use in humans and guinea pigs soon resulted in numerous, unexpected and severe reactions which were not related to the disease and which were termed serum sickness (v. Pirquet and Schick, 1905). At this time Portier and Richet (I902), who were studying the production of immunity to actinia toxin in dogs, found that if they were suitably spaced the injection of doses of toxin far below the toxic level produced severe and often fatal reactions. This reaction seemed to be opposed to 'prophylaxis' or 'immunity,' and they termed it ' anaphylaxis' or ' removal of protection.' This dual capacity of the same agent required explanation and v. Pirquet 
(I906) stated 'We are in need of a new, general, non-prejudicial word to designate the altered state which an organism achieves after acquaintance with any organic, living or inanimate poison.' $\mathrm{He}$ suggested the term ' allergy ' to designate this concept of altered capacity to react, and he grouped together both decreased reactivity or immunity and increased reactivity or hypersensitivity. With usage allergy has come to mean hypersensitivity, though v. Pirquet's unifying concept is still maintained by some workers (Sulzberger, 1940). v. Pirquet recognized the fundamental similarity, in both animals and man, of anaphylaxis and hypersensitivity produced by infection in spite of their different clinical manifestations. From that time on experimental studies in animals have contributed greatly to our understanding of allergic processes in man.

\section{Definition of Allergy}

v. Pirquet's definition outlines the basic aspects of allergic processes, and its essential truth after $5^{\circ}$ years of intensive study is a tribute to his interpretation. He defined allergy as the ' $a c$ quired specific altered capacity to react.' This definition will be amplified by dissection. ' $A c$ quired' implies previous adequate exposure to the sensitizing agent, the antigen or allergen. This is followed by an 'incubation period' averaging 8 to I4 days before the hypersensitive state is established. 'Specific' refers to the chemical composition of the antigen used to elicit reactions in sensitized subjects. 'Altered capacity to react' describes the reactions elicited, which may differ entirely from those produced by the initial exposure to the antigen, or may be out of all proportion to the dose required to elicit them, being enhanced in speed and severity. Allergic reactions fall into two main groups:

I. Immediate type hypersensitivity reactions, which include anaphylaxis, the Arthus reaction and allergic disorders in man such as hay fever, perennial rhinitis, asthma, urticaria and gastrointestinal allergy. The reactions elicited by the antigen come on within a few minutes and can resolve completely in one to two hours. The Arthus reaction differs in various respects and will be described later.

2. Delayed type hypersensitivity'reactions, which include the bacterial allergic, fungal, chemical and contact type reactions. These come on after a period of hours, are maximal at 24 to 48 hours and resolve themselves more slowly, taking perhaps several weeks before complete return to normal.

The participation of antibody in these reactions was conclusively shown by the passive transfer of anaphylactic hypersensitivity to normal animals by injection of the serum of sensitized animals (Otto,
1907; Richet, 1907). Similar proof was provided in human allergic disorders by Prausnitz and Kuestner (192I) who found that the injection of the serum of the latter, who was sensitive to fish, into the skin of his normal colleague transferred the hypersensitivity locally so that whealing reactions were obtained on testing the site some hours later with fish extract. More recently the transfer of delayed type hypersensitivity passively by means of lymphoid cells from sensitized subjects has been reported in both animals and man (Chase, I945; Lawrence, 1949, 1952). The combination of antigen and antibody initiates the allergic reaction and these terms will be discussed in more detail.

\section{Definition of Antigen ('gens' or former of antibody)}

Antigens are substances which have two actions:

I. They stimulate the production of antibodies after introduction into the body.

2. They react specifically with these antibodies either in vivo or in vitro or both.

Antigens are also called allergens in relation to clinical allergy, and allergens in turn have been called atopens and the corresponding antibody atopic or reaginic antibody, but these terms are no longer significant since the distinctions on which they were based have disappeared. The term antigen and allergen will be used here intefo changeably. The importance of protein in anti= gens was soon established and the early workers found that most proteins could act as antigens and that many antigens are protein or combine with protein to exert an antigenic action. Antigens can be divided into the following types:

I. Complete antigens or full antigens are substances which per se can produce hypersensitive states.

2. Incomplete or partial antigens combine with protein to become fully antigenic. Our knowledge $\frac{}{3}$ has been greatly extended in recent years due to the work of Landsteiner (1945), who made $\frac{0}{3}$ chemical substances antigenic by simple combination with protein. He found that many of these chemical substances, or 'haptens' as he termed $D$ them, possess labile nitro or chloro groups which combine readily with protein. By using chemical $N$ partial antigens of known composition, Land- $N$ steiner added precision to the immunological $O$ mechanisms concerned and contributed a concept $\omega$ of considerable importance for the understanding 2 of chemical and drug allergy and of the pathogenesis of certain diseases. Polysaccharides are $\mathbb{D}$ very effective partial antigens, whilst lipids are far $\stackrel{?}{-}$ less so and their specificity is not high. The re- $T$ port of Obermayer and Pick (1906) that homo- $\frac{D}{\mathbb{D}}$ logous protein can be made antigenic by chemical $\stackrel{\oplus}{\mathbb{D}}$ 
alteration before introduction into the body, has been extended by reports that partial antigens can become fully antigenic by combining with the body's own protein after introduction into the body, and these have been termed 'pro-antigens' (Gell, Harington and Rivers, 1946), or 'derivative antigens' because they are derived from both chemical and the body's own protein (Chase, 1952). This is the method by which hypersensitivity to chemicals and drugs arises in the ordinary way, and the significance of this concept will be discussed further in relation to partial antigens derived from infective agents and from the body's own tissue constituents. Once the hypersensitive state has been produced the partial antigens can elicit reactions though there is some doubt whether they need to combine with protein to do so. There is evidence that combination with protein is necessary for the elicitation of delayed skin test reactions, and Eisen, Orris and Belman (1952) found that out of eight 2-4-dinitrophenol compounds tested only those four which combined with protein elicited reactions.

\section{Specificity of Antigens}

The specificity of the antigens required to elicit. reactions depends on their chemical structure and antigens from different sources possessing similar superficial reacting groups react alike. Specificity may vary as follows:

1. Species or group specificity. Species specificity is of a high order and reactions may be elicited by only one compound or by extracts from one particular source. Group specificity is present when reactions are elicited by related compounds or extracts from related sources. Hypersensitivity to the sulphonamides provides examples where there is hypersensitivity to only one sulphonamide, or to the group of sulphonamides perhaps even including procaine derivatives which are chemically related.

2. Organ specificity has two aspects: (a) In subjects hypersensitive for example to injection of liver extract or insulin the reactions may be elicited by extracts from only a single species, such as the pig (species specificity) or by extracts of the particular organ from many animal species (organ specificity). (b) There is evidence to suggest that autogenous organ products may produce a hypersensitive state in which reactions occur in the specific organ. Hypersensitivity to lens protein is the classical example of this form. The above discussion of derivative antigens has already indicated that chemical alteration of the body's own proteins can render them antigenic.

\section{Definition of Antibody}

Antibodies are globulin substances produced in living tissue in response to antigenic stimulation and reacting specifically with the antigen in vivo or in vitro or both. It is the antibodies concerned with allergic reactions which will be discussed here, and these can be divided as follows:

1. Complete antibodies. These are also termed multivalent antibodies since the production of precipitates on combination with antigen is thought to be due to the formation of large aggregates for which multiple reacting groups are needed (Marrack, 195I).

2. Incomplete antibodies (Marrack, 1951). A feature of these is the absence of precipitation on addition of the antigen, which has led to the term 'non-precipitating antibody' being applied to them. Amongst the explanations for this failure to produce precipitates is the absence of adequate reacting groups for the production of the precipitate aggregates, and for this reason they have also been termed ' univalent antibodies.' If an antigen is added in one stage to antibody containing serum, larger amounts of antibody are precipitated than are produced by the addition of the antigen in fractions and in stages, and the presence of residual antibody in the latter case is shown by the production of passive anaphylactic sensitization on injection of the supernatant serum, after removal of the precipitate, into a normal subject (Kabat, 1952). It is suggested that the addition of the antigen in one stage leads to the formation of large aggregates which carry down the "non-precipitating' or incomplete antibody. Thus the same type of antibody, namely incomplete antibody, can function as both passive transfer skin-sensitizing antibody in man and as passive transfer anaphylactic antibody in animals. In the past the presence of precipitins in hypersensitive animals and their absence in allergic man was thought to represent a difference between hypersensitivity in man and animals, but this recent work emphasizes their basic similarity.

3. Blocking antibody. One of the problems which has not been explained as yet is the production of skin sensitizing antibody in response to contact with an allergen, such as pollen, by the ordinary route, i.e. by inhalation or contact, and the production of a 'blocking antibody' when pollen extracts are given by injection (Cooke, Barnard, Hebald and Stull, I 935 ; Loveless, 1940, 1943; Harley, 1937). The blocking antibody (to be distinguished from the term 'blocking antibody' as used in haematological work) prevents the antigen from eliciting reactions in sensitive subjects, but it is only temporarily present in the serum of treated subjects or in passive transfer tests, in contrast to skin sensitizing antibody which may persist for life in actively sensitized subjects. The complexity of the antigens used may be im- 
portant because the blocking antibody may be a response to antigenic fractions which are not concerned with hypersensitive reactions. The route of administration may also be responsible for the different types of antibody.

Recent evidence indicates that antibodies are formed in the reticulo-endothelial system, particularly the lymphoid-plasma cell series, and a comprehensive survey is given by Barber and Delaunay (1952). The role of circulating lymphocytes is not yet clear, though it has been shown that they produce passive transfer of delayed type hypersensitivity (Chase, 1945), and there is evidence that they can also produce passive transfer of immediate type hypersensitivity (Chase, I95 I).

\section{Immediate Type Hypersensitivity}

I. Production of the hypersensitive state.

2. Antigen-antibody reactions.

3. Clinical manifestations: (a) Anaphylactic shock; (b) local allergic inflammation and (c) general allergic inflammation.

\section{Production of the Hypersensitive State}

Anaphylactic hypersensitivity can be produced actively and passively. Active sensitization is produced by administration of the antigen by ingestion, inhalation or injection. The initially harmless antigen can be effective in minute amounts and, as a rule, provokes no local reaction. Larger protein molecules are more effective than smaller, and both can be enhanced by adsorption on to inert substances such as charcoal and kaolin or by injection together with adjuvants such as liquid paraffin or after alum precipitation. Coulson and Stevens (1949) found that the subcutaneous injection of $0.04 \mu \mathrm{g}$. of alum precipitated albumin into guinea pigs was as effective as twice that dose given intravenously and 60 times the dose given intraperitoneally in producing hypersensitivity. The incubation period is 8 to 14 days on the average, and once present hypersensitivity can persist for life. The length of the incubation period depends on the nature of the antigen, and Doerr and Berger (1922) report that horse serum albumin requires a longer period than the euglobulin, and that very small doses also lengthen the incubation period. Repeated subcutaneous injections of protein antigens at intervals of several days into rabbits and guinea pigs leads, after three to five injections, to a severe, necrotic and haemorrhagic reaction named after Arthus, who described it in 1903. The reaction in these animals comes on after three to four hours and is not readily reversible.

Passive transfer of hypersensitivity locally or generally is produced by injection of the serum of sensitized animals into normal recipients and re- actions are elicited by subsequent administration of the antigen. This process can be reversed, the antigen being injected first followed by the injection of the antibody containing serum (Wright $\stackrel{\varrho}{c}$ and Hopkins, I94I). The sensitivity can be transferred to other species though the type of $\stackrel{\vec{\rho}}{\rightarrow}$ reaction elicited may vary, thus, horse anti- 0 pneumococcus serum transfers immediate wheal $\frac{C}{=}$ or Arthus type reactions to the guinea pig, the $\frac{\bar{\omega}}{\vec{D}}$ skin reactions being elicited by the specific pneu- $\odot$ mococcal carbohydrate (Mehlman and Seegal, क 1934; Kabat, 1952). It also transfers the Arthus क type - sensitivity to the rabbit and the anaphylactic type to the dog (Francis and Tillett, I93I). $\overrightarrow{\vec{\omega}}$ The anaphylactic antibody has been studied by $\stackrel{\omega}{\omega}$ Kabat and his colleagues, and they report that $\overparen{B}$ non-precipitating antibody is as efficient as pre- 3 . cipitating antibody in transferring anaphylactic iู sensitivity to the guinea pig, though non-pre- is cipitating antibody does not transfer Arthus type $\mathscr{\omega}_{\omega}^{\omega}$ hypersensitivity (Kabat, 1952). There is a cor- $\omega_{j}$ relation between the precipitin titre and the $\stackrel{\sigma}{\rightarrow}$ Arthus reaction in both actively and passively sensitized animals (Opie, 1924), and it is thought $\rightarrow$ that the precipitate damages the vessels. The $\subseteq$

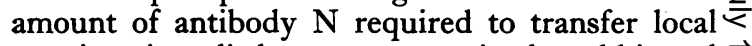
reactions is as little as $0.025 \mathrm{mg}$. in the rabbit and $\vec{\oplus}$ $0.09 \mathrm{mg}$. in the guinea pig (Fischel and Kabag of 1947; Benacerraf and Kabat, 1949). The in jection of $0.03 \mathrm{mg}$. of antibody $\mathrm{N}$ into a 250 g guinea pig produces anaphylactic sensitivity which can be shown on testing 48 hours later when neither this dose nor five times the dose of anti- $\frac{D}{\mathbb{D}}$ body can be detected in the serum by in vitro tests, indicating the sensitivity of the biological 0 reaction (Kabat, Coffin and Smith, 1947). Kabat has calculated that in passively sensitized guinea pigs the uterus may contain $10^{-5} \mathrm{mg}$. of antibody $\mathrm{N}$ and will react by contraction on contact with the antigen in vitro.

\section{Antigen-Antibody Reactions}

In vivo antigen-antibody reactions initiate com- 을 plex biological changes which determine the 0 clinical picture, and they can be a very sensitive indicator of the presence of antibody and of the $\frac{7}{0}$ chemical specificity of the antigen. The early controversy regarding cellular or humoral mechan- $N$ isms in allergic reactions was settled for a time in $N$ favour of the cellular mechanism by Dale's demonstration that isolated washed smooth muscle $\frac{\omega}{\sigma}$ tissue from sensitized animals reacted in vitro on? addition of the antigen, and that the tissue mayc then be desensitized and not react to further addition of the same antigen. Sollmann and ${ }^{+}$ Gilbert (1937) and Gilbert (1938) report that visible contractions of the pulmonary vessels and $\underset{\mathbb{D}}{\mathrm{D}}$ the bronchi of sensitized rabbits can be seen in $\frac{\stackrel{\rho}{\mathbb{Q}}}{\mathrm{O}}$ 
thin sections of lung after the addition of the antigen. Similar reactions of the bronchial muscle of human asthmatics have been reported by Rosa and McDowell (195I) and Schild, Hawkins, Mongar and Herxheimer (195I).

The possibility of a humoral mechanism in anaphylaxis was suggested by the report of Dean and Webb (1924) and Webb (1924) that there is a marked leucopenia in anaphylactic dogs and that the capillaries of the lungs are crowded with enormous numbers of leucocytes which are firmly adherent to the vessels. This aspect has recently been re-investigated by é Silva (1950) who has shown that the injection of antigen into sensitized animals is followed by the rapid formation and disintegration of microthrombi of platelets and leucocytes in the capillaries. This is followed by the liberation of histamine and plasma protease activators which, he suggests, pass into the tissues there leading to the further liberation of histamine heparin, adenosine and other metabolites. Exclusion of the liver from the circulation prevents the liberation of heparin. The heparin is probably responsible for the decreased coagulability of the blood in anphylactic shock. The localization of the thrombi may be aided by the contraction of the vascular smooth muscle which is a shock tissue in this type of reaction. Similar microthrombi have been reported in Arthus reactions (Stetson, I95I). In the perfusion of sensitized organs é Silva found that the use of whole blood as a vehicle for the antigen led to much greater histamine liberation. In addition to the enzyme release of histamine suggested by é Silva, the action of other histamine liberators, such as simple diamines described by McIntosh and Paton (1949), must also be considered. The relationship between these reactions and the thrombocytopenia and leucopenia of acute allergic reactions remains to be clarified.

The most important metabolite so far identified is histamine, which can reproduce many but not all the anaphylactic and allergic manifestations. Dale (1948) has suggested that histamine may be extrinsic or intrinsic, the extrinsic histamine acting on tissues away from the point of liberation and the intrinsic being liberated in close proximity to the reacting cells, and he suggests that this may explain the failure of anti-histaminic drugs to prevent the allergic reactions in conditions such as asthma. The presence of histamine in the circulating blood cells has been discussed by Code (1952), who reports that in the rabbit the platelets are rich in histamine whereas in humans it is contained in the granulocytes, and he points out that the eosinophile leucocyte which has been suspected of carrying histamine does not always contain it in spite of raised histamine content of the blood.

\section{Clinical Manifestations}

The tissue reactions are based on smooth muscle contraction and increased capillary permeability both of which are produced by histamine. Abell and Schenck (1938) observed directly the vascular reactions produced by addition of antigen to a transparent chamber in the rabbit's ear, and they found that there was arteriolar spasm, circulatory slowing and formation of white cell thrombi and later diapedesis of white cells into the tissues. Similar vasospasm has been reported in various species including the mouse, in which anaphylactic shock produces vasoconstriction of the ear vessels (McMaster and Kruse, 195 I). The dependence of the Arthus reaction on blood vessels is reported by Rich and Follis (1940) who found that it could not be produced in the avascular cornea, but appeared in the cornea after it had become vascularized as a result of damage.

(a) Anaphylactic shock. With time the term anaphylactic shock has been used chiefly to describe the reactions in experimental animals, but similar shock occurs in humans as well. There are also increasing reports of allergic conditions in animals like those occurring in humans, such as hay fever, asthma and eczema (Redding, I949: Wittich, 1949), which have the same features and indicate the common fundamental biologicaf nature of the allergic reaction. The clinicat picture varies in different species and is often dependent on the distribution of smooth muscle in the body and on the vulnerability of the shock organ and the sensitivity to histamine. Anaphylactic shock in man presents many of the reactions found in the commoner experimental animals and consists of local and generalized urticaria and angioneurotic oedema, bronchial spasm and mucosal oedema, gastro-intestinal symptoms, shock, collapse and perhaps death. Anaphylactic shock has been reported following the ingestion of very small amounts of milk in milk sensitive infants (Campbell, 1945). The injection of too strong doses of pollen into hay fever subjects can readily be followed by severe shock, and anaphylactic death has been recorded after skin test doses of various allergens (Urbach and Gottlieb, 1946). Another common example is bee or wasp sting sensitivity in which not only is there a high degree of hypersensitivity to the insect protein but the sting contains hyaluronidase which must certainly enhance the rate of absorption of the antigen and the severity of the shock.

The vulnerability of the shock organ may overshadow the clinical picture and in the guinea pig death rapidly ensues, due to respiratory failure produced by bronchospasm and mucosal oedema leading to acute emphysema and great distension 
of the lungs. It was the resemblance of this syndrome to asthma in humans which suggested to early observers that this disease might have an allergic basis, though very pertinent observations regarding an ' allergic' mechanism in asthma had been made on clinical grounds 50 years previously (Hyde-Salter, I 868). In the rabbit death results from spasm of the pulmonary arterioles leading to acute right heart failure, and in the dog gastrointestinal symptoms predominate and death follows after some hours. The hepatic veins of the dog contain a high proportion of smooth muscle, and their constriction makes the liver a shock organ. The exclusion of the liver from the circulation prevents the anaphylactic shock.

(b) Local allergic inflammation. Local allergic reactions, like the wheal or oedema of the nasal mucosa, resolve rapidly except for the eosinophile infiltration which can persist for several days. More severe irreversible reactions are found in the Arthus reaction, in which there are necrosis and rupture of the minute blood vessels, thrombi of leucocytes plugging the capillaries and cellular infiltration into the tissues. This reaction has been correlated with the precipitin titre (Opie, 1924). The blood vessels and circulating white cells participate in the reaction which can be elicited in all parts of the body except for the avascular cornea (Rich and Follis, 1940). Beatrice Seegal has used the reverse Arthus reaction to demonstrate how shock organs can be determined. In this reaction a second intravenous injection of antigen produces a local reaction at the site of the first injection of antigen. Seegal found that if the antigen was injected into the anterior chamber of the eye the subsequent intravenous injection elicited a reaction in that eye. In addition, the production of a non-specific inflammation in one eye by the injection of glycerine leads to localization of the antigen in that eye if the first injection of antigen is given intravenously. Subsequent intravenous injection of the antigen leads to a reaction in that eye, thus indicating the importance of inflammatory processes in the production of local sensitization and the production of a potential shock organ should the subject be exposed to the specific antigen again (Seegal and Seegal, I93 I, 1933). The injection of antigen into the pericardium of the rabbit also produced local sensitization more frequently than injection elsewhere in the body, and perfusion of the coronary vessels with the antigen decreased the flow by 15 to 45 per cent. (Wilcox and Andrus, 1938; Seegal and Wilcox, 1940).

(c) Gentral allergic inflammation. Serum sickness provides the classical example of general allergic inflammation and was described with the atmost clarity by v. Pirquet and Schick (1905).
Serum sickness presents the typical incubation period averaging 8 to 14 days and produces the $\frac{2}{3}$ same clinical manifestations found in other types of $\mathbb{Q}$ hypersensitivity such as drug allergy. Pyrexia, $c$ urticaria and anioneurotic oedema, splenic and lymph gland enlargement, arthralgia and arthritis, $\stackrel{\vec{P}}{+}$ gastro-intestinal and pulmonary disturbances ap-읃 pear as well as lesions in any part of the body. The $\frac{\bar{\sigma}}{\bar{N}}$ injected serum proteins can be found in the circula- $\frac{\bar{s}}{\vec{D}}$ tion for weeks and the flare-up of the condition $\stackrel{\curvearrowright}{\triangle}$ which occurs at intervals has been correlated with the persistence of different serum proteins which $\overrightarrow{ }$ vary in the time they take to elicit reactions. The? foreign serum proteins disappear rapidly at the $\vec{\omega}$ time of appearance of antibodies, at which time the serum sickness develops (MacKenzie and Leake, 8 1921; Seegal, 1952). Where the foreign serum 3 . proteins persist without antibody production the तु serum sickness does not appear. The re-injection of foreign protein into sensitized subjects is fol- $-\underset{\omega}{\omega}$ lowed by its rapid breakdown and disappearance $\omega_{-j}$ as compared with its injection into normal animals (Wright and Laws, 1952), suggesting that this은 rapid breakdown and disappearance may be afunction of the hypersensitive state.

The production of vascular reactions and of diffuse lesions resembling periarteritis nodosa foll- $\overrightarrow{0}$ lowing the injection of large doses of foreign serufict into rabbits was described by Klinge (1929), a a d the allergic concept in relation to these vascupro lesions has recently been re-emphasized by $\mathrm{Rich}$ and Gregory (1943). The collagen lesions found® in serum sickness in association with the vascularō

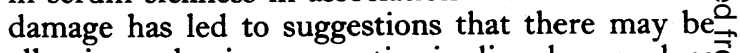
allergic mechanisms operative in disorders, such aso acute lupus erythematosis, scleroderma, malignant nephrosclerosis, rheumatic fever as well as peri arteritis nodosa. There are, however, reasons for being cautious in making a diagnosis of an allergic etiology on the basis of histological evidence alone(Klemperer, 1947), though allergy provides tempting explanation for these obscure diseases.

The nature of the antigen influences the type of vascular lesion, and More and McLean (1949) re-o port that horse serum results in a diffuse arteritis? whilst bovine gamma globulin produces glomerulo nephritis and granulomatous endocarditis in ad dition. Hawn and Janeway (1947) report thats crystalline bovine albumin appeared to be a poor antigen in rabbits, disappearing slowly from the circulation and producing disseminated lesions $\omega$ resembling periarteritis nodossa after two to three weeks, whereas bovine gamma globulin dis $\frac{0}{5}$ appeared more rapidly and the lesions found were? not disseminated and were predominantly in the myocardium and glomeruli. The production of vascular lesions seems to be favoured by the use of large doses of antigen which persist for lon 
periods, perhaps thereby producing an enhanced degree of hypersensitivity. This resembles in some respects the forced antigenic stimulation of the Arthus reaction with its characteristic local vascular damage.

\section{Delayed Type Hypersensitivity}

(a) Production of delayed type hypersensitivity. (b) Antigen-antibody reaction.

v. Pirquet recognized the 'allergic' nature of the enhanced speed of reaction of vaccination of previously vaccinated subjects described by Jenner and Bryce (Hektoen, 1932), and of the enhanced speed and severity of re-infection of tuberculous animals. Fungi, many other infective agents and chemical sensitizing agents elicit reactions in hypersensitive subjects which come on after several hours and are maximal after 24 to 48 hours. In those diseases in which hypersensitivity plays a part these reactions are first elicited at about the same time that the first manifestations of the disease appear (Sulzberger, 1940). The problem of the relationship between hypersensitivity and immunity arises at this point, and it would appear that since the hypersensitivity is a sine qua non of the disease it is harmful. But the altered enhanced reaction which hypersensitivity brings about may be locally harmful and generally beneficial. In fungal infections, for example, the more severe the inflammatory response the higher the degree of hypersensitivity, the more rapid the cure and the more difficult the demonstration of the pathogen, and it is claimed that the hypersensitive inflammatory reaction leads to more rapid destruction and throwing off of the fungi. More indolent fungal infections are more chronic and more difficult to cure (Sulzberger, I940). The degree of hypersensitivity and the site of reaction are also important, and a severe tuberculin skin reaction cannot be compared in its end result with a similar reaction in a vulnerable bronchus. The terms immunity and hypersensitivity have been used chiefly to describe the end results of reactions in which they participate, but this should not obscure the fact that they have a common basic mechanism, namely the antigen-antibody combination. The complicating factors such as those briefly described may result in widely differing end pictures under varying circumstances.

The antigenic complexity of bacteria, which contain protein carbohydrate and lipid, influences the type of hypersensitivity produced and the reactions elicited. Bacterial proteins like other proteins produce and elicit immediate type hypersensitivity and reactions when injected by them selves. They are, however, partially antigenic in relation to delayed type hypersensitivity since they cannot produce it by themselves, though they elicit delayed reactions on testing subjects in whom delayed type hypersensitivity has been produced by infection. This partial antigenic of tuberculin, for example, is important since Rich claims that desensitization with tuberculin can remove hypersensitivity and leave the immunity. But tuberculin has been found in avirulent as well as virulent strains (Seibert and Morley, 1933), and it would not appear to be the factor responsible for invasiveness. This, together with its inability to produce delayed type hypersensitivity, suggests that another antigenic fraction may be responsible for the immune state and that desensitization with tuberculin is ineffective against it. The findings of Bailly (1950) support this possibility, for she found that in animals immunized against haemolytic streptococci, the intravenous injection of the carbohydrate fraction produced desensitization against it but left the immune state intact, whereas desensitization with the protein antigenic fraction deprived the animals of their immunity. If only the carbohydrate antigenic fraction had been studied separation of immunity from hypersensitivity would appear to have been produced.

The polysaccharides of organisms such as streptococci, pneumococci and meningococci are also partial antigens in relation to delayed type hypersensitivity since they elicit immediate wheas type reactions in sensitized subjects as a rule, but they cannot produce the delayed type hypero금 sensitivity. Lipids are weakly antigenic, but the report by Raffel $(1946,1948)$ that purified tubercle wax injected together with tuberculoprotein produces the delayed type hypersehsitivity may give some indication of their immunological role.

(a) Production of delayed type hypersensitivity. This can be produced both actively and passively, but unlike immediate type hypersensitivity in which the injection of the protein antigen need not provoke a local reaction, for the production of delayed type hypersensitivity, either an active infection even with attenuated strains, or the use of adjuvants with bacterial antigens is required to produce hypersensitivity consistently. Adjuvants such as liquid paraffin injected together with killed tubercle bacilli will produce a high degree of delayed type hypersensitivity, and Raffel (1946, 1948) has recently reported that tubercle wax plus tuberculoprotein will also do so. The importance of the local reaction excited by the adjuvant is suggested by the report of Dienes and Schoenheit (1929) that injection of protein antigen such as egg white into tuberculous foci leads to the production of delayed type hypersensitivity with delayed type reactions on testing subsequently with egg white. Raffel, Arnaud, Dukes and Huang (1949) report that the injection of egg white with tubercle wax also produces delayed type hypersensitivity to- 
wards the egg white. It seems that the active infection or the adjuvant may assist production of the hypersensitive state by prolonging the antigenic stimulation, or the mononuclear cellular infiltration produced by the adjuvants may be participating as suggested by Burnet by taking up the antigen, altering it and setting in motion the antibody forming mechanism. The significance of local retention of the bacterial antigen is indicated by the report of Derick and Swift (1929), who found that the intravenous injection of streptococci failed to produce hypersensitivity, whereas injection into the knee, muscle or peritoneal or pleural cavities did produce hypersensitivity. Delayed type reactions are also obtained during the early stages of sensitization to foreign sera to be succeeded later by immediate type reactions (Dienes and Simon, r935; Mote and Jones, 1936). These findings have led to the view that delayed type hypersensitivity is a stage in the development of immediate type sensitivity and this fundamental problem needs further elucidation.

Contact type hypersensitivity lends itself to controlled study of delayed type hypersensitivity. The sensitizing capacity of the chemical depends on the concentration, and dilute solutions of primulin, for example, will sensitize 42 per cent. of subjects whereas 100 per cent. are sensitized by concentrated solutions (Bloch, 1926). The route of administration is also important and Chase (1946) found that prior feeding of the chemical inhibited the later production of cutaneous sensitization with it. This refractory state persists and is specific since it does not prevent sensitization to other chemicals. The refractory animals could be passively sensitized by injection of cells from sensitized animals so that they reacted for a time to the chemical under consideration. Chase (1949) interprets this as an indication that the refractory state is not due to a blocking antibody which would perhaps have prevented the reactions. The mechanism of this inhibition of sensitization is not known, and it is noteworthy that feeding of the chemical after sensitization was found to have no effect on the hypersensitivity. Landsteiner and Chase (1940) and Chase (I94I) have also reported that the production of contact sensitization is influenced by heredity since they bred poorly and easily sensitized strains of guinea pigs.

The association of immediate and delayed type hypersensitivity both of which are produced in bacterial allergy and in hypersensitivity to chemical partial antigens, is important in relation to hypersensitivity to chemical and antibiotic therapeutic agents. Where these are acting as contact sensitizers diagnostic patch tests are effective in producing delayed type reactions, and with those agents producing immediate type hypersensitivity such as the injection of liver extracts and insulin $\frac{2}{3}$ immediate type reactions are obtained on testing. $\frac{\mathbb{Q}}{\not}$ These are only a small part of the drug hyper- $c$ sensitive group, and improved methods of testing for the remainder are urgently needed. In hyper- $\stackrel{S}{+}$ sensitivity to chemical partial antigens the chemical 0 by itself can elicit delayed type contact reactions on $\frac{\bar{O}}{\bar{D}}$ application to the skin and may also produce ana- $\frac{\bar{\omega}}{\partial}$ phylactic reactions on injection. Where the $\stackrel{\mathbb{Q}}{\varrho}$ chemical by itself produces anaphylactic reactions \& it is thought that it combines with the body's own protein, but Chase (1952) points out that he ob-? tained anaphylactic reactions in certain cases only $\overrightarrow{\vec{\omega}}$ when the chemical had been conjugated with pro- $\stackrel{\sim}{\sim}$ tein before injection into the body, and he suggests 8 that the use of proper conjugates may be of value. 3 . Rajka and Hegyi (1950) report that they obtained iु immediate type whealing reactions on injecting the serum of subjects sensitive to sulphonamides, $\underset{\omega}{\omega}$ arsenicals and barbiturate into the skin of normal $\omega$ subjects to whom the drug under investigation $\rightarrow$

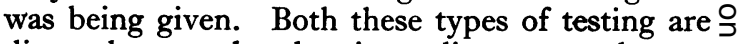
directed towards the immediate type hyper- sensitivity. It seems that investigations along the $\subseteq$ lines indicated by the experimental study of $\rightleftharpoons$ chemical partial antigens will take into account the $\vec{\oplus}$ different types of hypersensitivity and the natue of the antigens used to produce them, together. with the appropriate method of testing.

(b) Antigen-antibody reaction. The location of the reacting antibody in immediate type hypersensitivity can be determined by the reactions $\frac{\circ}{\Phi}$ which occur in vessels and smooth muscle both in $\stackrel{2}{\Rightarrow}$ vivo and in vitro. With delayed type reactions the site of the antigen-antibody reaction has only $\frac{3}{2}$ become clearer in recent years. Because of the ability of tuberculin to elicit reactions in all parts of the body including the avascular cornea Rich $\frac{}{3}$ (1940) suggested that all the cells of the body are sensitized and he supported this with his observa- 3 . tions of the toxicity of tuberculin for tissue cultures from hypersensitive animals. This cytotoxic 3 action of tuberculin has since been reported by a number of workers (Rich and Lewis, I932; Moen and Swift, 1936; Aronson, 1931; Heilman, $\frac{7}{0}$ Feldman and Mann, I944; Fabrizio, 1952), though some of the reports are not entirely con- $N$ vincing and Baldridge and Kligman (195I) failed $N$ to repeat Rich's findings and cited the technical difficulties in assessment of this method. Moen ${ }^{\omega}$ (1936) reported that streptococcal protein is toxic for tissue cultures from streptococcal sen- $\stackrel{0}{\complement}$ sitive animals. Raffel et al. (1949) have reported that the delayed type sensitivity to egg white + produced by injection of egg white with tubercle $\frac{0}{0}$ wax, is associated with a similar cytotoxic action $\overrightarrow{\mathbb{D}}$ of egg white for bone marrow tissue cultures $\frac{O}{\mathbb{Q}}$ 
from sensitized animals. In immediate type hypersensitivity the antigens are not toxic for tissue cultures from hypersensitive animals and Raffel's findings support the claim that delayed type hypersensitivity is produced by protein antigens under the conditions described (Meyer and Loewenthal, 1927).

The cytotoxic action of tuberculin has so far been demonstrated with tissue cultures of reticuloendothelial tissues, such as lymphoid, splenic, bone marrow, circulating white blood cells and cells obtained from mononuclear cellular exudates into the peritoneal and pleural cavities. Cruickshank (195I) and Everett, Livingood, Pomerat and Funan (1952) have reported that tuberculin is not toxic for tissue cultures of skin from hypersensitive animals. The emphasis on cells of reticuloendothelial origin was heightened by the reports of Landsteiner and Chase (1942) and Chase (1945), that contact and tuberculin hypersensitivity are passively transferred by injection of mononuclear cellular exudate or lymphoid or splenic cells, delayed type reactions being obtained on testing after an appropriate interval. Lawrence (1949, 1952) reported successful passive transfer of tuberculin and streptococcal sensitivity in humans by injection of circulating white cells, and he found that the intensity of reactions elicited depended on the dosage of cells and the concentration of the antigen injected.

The antibody carrying cell has been identified as the lymphocyte and Wesslén (1952) has used pure lymphocyte suspensions from thoracic duct lymph for successful passive transfer whilst Kirchheimer et al. (I95I) reported that neutrophile cellular exudates failed to transfer the hypersensitivity. The relationship between the number of lymphocytes and the dose of antigen has also been reported by Wesslén, who found that the intensity of the reaction depended on these quantitative factors. The report that passive transfer of tuberculin hypersensitivity was not inhibited by cortisone administration to donor or recipient (Cummings and Hudgins, 1952) though it does inhibit the tuberculin reaction in actively sensitized subjects, indicates once more the importance of the cells in determining the reaction. The belief that all types of cell are sensitized in delayed type hypersensitivity is not borne out by these findings, which suggest that the delay in the onset of reaction is, in fact, a reflection of the time required for the arrival of enough antibody carrying lymphocytes and that the blood vessels must participate functionally by conveying these cells to the neighbourhood of the reaction. Histological evidence shows that tuberculin reactions start within the first one to two hours (Laporte, 1934) and it seems likely that the macroscopic reaction may only appear when enough sensitized cells have reacted with the antigen to excite the inflammatory process.

Favour (1947) and his colleagues have reported that tuberculin lyses lymphocytes from sensitized subjects in vitro within 20 minutes, and this, too, indicates that the antigen antibody reaction is far more rapid than the macroscopic reaction suggests. Miller and Favour (195I) also reported that the sensitized lymphocytes liberate a plasma factor which can sensitize normal cells and make them susceptible to lysis by tuberculin, though Wesslén (1952) was unable to confirm this. The functional participation of the underlying blood vessels in epidermal reactions in humans is suggested by the findings of the author in investigations to be reported elsewhere. It was found that the intradermal injection of adrenaline with tuberculin inhibits the reaction, and histological study of three and 24 hour skin biopsy specimens from these and control areas shows a striking decrease in the infiltrating cells in the adrenalin tested areas. It seems likely that the vasoconstriction produced by the adrenaline temporarily lessens the local circulation and slows the access of circulating antibody carrying cells. By the time the adrenalin effect has worn off after Io to 12 hours, the local concentration of tuberculin has probably decreased below.the reacting level. Whilst the resting reticuloendothelial cells must certainly take part in the later stages of the reaction, it would seem that it is the immigration of circulating lymphocytes that brings about the main reaction.

The influence of agents which modify tuberculin reactions may be exerted at various points. Cortisone, for example, is a lymphopenio agent thus reducing the number of available antibody carrying cells, and in histological study of cortisone inhibited tuberulin reactions Gell and Hinde (I95I) report that the decrease in mononuclear cells is the most prominent feature. Cortisone also enhances the vasoconstrictor tone of blood vessels and reduces the endothelial damage in reactions to tubercle bacilli (Ebert and Wissler, I95 I ; Ebert, 1952; Humphrey, 195I). The secondary antibody response is also reduced by cortisone (Halpern et al., 1952) though this aspect is not yet clear owing to the variety of experimental conditions used by different workers. The non-specific antiinflammatory action of cortisone would act after the combination of antigen and antibody and decrease the reaction in that way (Michael and Whorton, I951 ; Dougherty and Schneebeli, 1950). Irradiation also inhibits tuberculin reactions and Lennox, Dempster and Boag (1952) suggests that this is due to an alarm stimulus with adrenocortical response, i.e. a cortisone response, but irradiation also decreases the number of lympho- 
cytes directly and the quantitative reduction of antibody carrying cells may be a cause of the inhibition as well. A possible similar mechanism for the ' desensitizing ' action of the agents, described by Long, Miles and Perry (195I) D'Arcy Hart, Long and Rees (1952) and Cornforth and Long (1952) which inhibit tuberculin reactions does not appear to have been investigated. Among these the sphingomyelin group have been reported to produce a lymphopenia (Fisher, Harington and Long, I95I), but there is so far no indication of the mode of action of dehydroascorbic acid, of the organic phosphates such as glucose I phosphate and glucose 6 phosphate and of the ergot derivative, lysergic acid, which acts on the hexose monophosphate of the blood, or of the surface acting agents such as the polyoxyethylene ethers. These may act at various and differing points along the sequence of antigen and antibody combination already described, or on the inflammatory response of the tissues to the combination of antigen and antibody.

Antihistaminic drugs do not produce a lymphopenia and their inhibitory action on tuberculin reaction in guinea pigs reported by Sarber (1948) and amply confirmed by the author may be due to the actions of these drugs on blood vessels at the tuberculin test site. This inhibition is produced if the drug is given in adequate dosage and well before the test is carried out. It seems possible that by their inhibition of vascular reactions the antihistaminic drugs may impair the functional participation of the vessels in bringing about the reaction thus reducing the available number of antibody containing cells, or they may reduce the vascular inflammatory response which follows the combination of antigen and antibody. The rationale of these inhibitory factors will only be comprehensible when it is understood at which point the drugs used will exert their action, and the actions of cortisone for example are directed not only against the condition being treated but against the defence mechanisms as a whole, leading to enhancement of infection, bacterial and virus, which is being reported with increasing frequency in experimental animals.

\section{Hypersensitivity to the Body's own Tissue Products}

The concept of 'horror autotoxicus' of the early immunologists implied that the body could not produce antibodies against its own tissue constituents, but this has had to be modified in recent years by the demonstration that homologous protein and the body's own protein can act as partial antigens. The development of organ specific sensitization to the body's own protein was suggested by Verhoeff and Lemoine (I922),
Courtney (1929) and Woods (1940), who claimed that lens protein and uveal tissue protein liberated by trauma could produce a hypersensitive state in which the antibodies would combine with and produce reactions in the particular organ. They suggested that this is the explanation of the endophthalmitis phaco-anaphylactica and sympathetic ophthalmia which after an interval of days follow trauma to the lens or uveal tissue. Positive skin tests to lens protein derived from various species, i.e. organ specificity, have been reported in these cases and 'desensitization' with lens protein before operation has been stated to decrease the incidence of reactions (Goodman, 1935). The experimental production of organ specific hypersensitivity with homologous tissue was reported by Burky (1934), who injected bacterial products such as staphylococcus toxin as adjuvants with lens protein and muscle. In sensitized animals trauma to the lens or muscle produced reactions out of proportion to the injury, and it is suggested that the liberation of the organ protein by trauma provided the antigen for combination with the antibody produced by sensitization. Similar results have been reported by Lucic (1939) using a mixture of uveal tissue and toxin as the antigen.

Whitfield (1922) suggested that auto-sensitization to skin breakdown products occurs in skip diseases and.leads to extension and persistence of the condition, and Hecht, Sulzberger and WeT (1943) have produced anti-skin antibodies b $\vec{y}^{\prime}$ injecting skin extracts plus staphylococcal toxin into experimental animals. Auto-antibodies to homologous skin have been demonstrated by Zoutendyk and Gear (1950) in patients with lupus erythematosis.

The production of disseminated encephalomyelitis by injection of homologous brain plus adjuvants such as liquid paraffin and tubercle bacilli has been reported by Morgan (1946, 1947) and Kabat, Wolf and Bezer (1946, 1947). Antibodies to normal lung tissue have been reported in atypical primary pneumonia by Thomas et al. (1943), and to human heart in rheumatic fever by Cavelti (1945).

With increasing refinement of bacterial ant $D$ tissue antigens these problems will probably be clarified, since some findings such as the pro- N duction of experimental nephritis by these methods described by Cavelti and Cavelti (1945) has not $N$ been confirmed by Humphrey (1948). This pos- $\mathbb{\omega}$ sibility is suggested by the report of Glynn and 0 Holborrow (1952) that the injection of a mixture $\varrho$ of chondroitin sulphate, which is a normal con- $\mathbb{D}$ stituent of the collagen of the body, together with $\stackrel{\oplus}{+}$ haemolytic streptococci produced a hypersensitive $\frac{T}{T}$ state in which mesenchymal lesions such as arthritis were produced and immediate whealing 
reactions were obtained with the carbohydrate partial antigen. The amount of carbohydrate required was minute and the findings are highly significant since the ease of formation of the antigen from the chondroitin seems within the range of normal infection. Where such a hypersensitive state has been established it seems that both liberation of the tissue partial antigen or infection with the specific organism could elicit reactions in the particular tissue from which the partial antigen is obtained.

\section{Clinical Allergic Disorders in Man}

There is no explanation for the characteristic ease of sensitization of so-called allergic subjects, and no difference in the basic antigen-antibody mechanisms has been demonstrated between ' allergic' and sensitized non-allergic human subjects, or between them and experimental hypersensitivity in animals. The antigen-antibody reaction initiates all the phenomena of allergic conditions in man under controlled experimental conditions, but in clinical practice these reactions are complicated by many other factors which are secondary. The concept of the 'allergic equilibrium' makes it possible to assess these factors objectively. The " allergic state' and the ' allergic condition' should be distinguished, and since we have no means of altering the constitutional allergic background the management of the condition must be directed towards maintaining a 'sub-clinical' allergic state. Increased allergic insult or the supervention of factors such as infection, endocrine, psychosomatic and other causes may overcome the clinical threshold and precipitate the condition. At this stage the antigen-antibody reaction may remain the initiating factor and a direct allergic approach is possible, but where the clinical condition has acquired its own momentum, precipitating factors of many sorts can maintain the disorder. The tipping of the balance in favour of the subject by a decrease of the allergic insult frequently leads to tolerance of the secondary factors which then no longer produce the clinical disorder. The large number of possible combinations of factors which can operate to the patient's disadvantage also contain instances where control of secondary factors reduces the condition to a sub-clinical level, and this accounts for the many and varied methods of treatment of allergic disorders for which good results are claimed.

The controlled experimental studies which have been - described, however, indicate that decreased exposure or avoidance of the antigen will prevent the development of sensitization, a point of considerable importance in children in allergic families in whom the hereditary factors enhance the likelihood and early appearance of clinical allergic disorders. To take only two examples of the application of our understanding of this aspect, protection from the recognized commoner allergens is therefore of value in infancy and is of importance in regard to domestic and occupational exposure in later life. Where sensitization has already been established avoidance or decreased exposure to the antigen is once again the most fundamental method of control, for the full exercise of which the environmental contacts of the patient should be thoroughly familiar to the physician. 'Desensitization' or, to use a preferable term, 'hyposensitization' leading to decrease in sensitivity or increased tolerance is another method of decreasing the effects of the antigens where continued exposure cannot be avoided. To attempt to approach clinical allergic disorders only by non-specific methods and by palliative treatments which do not influence the antigen-antibody mechanism on which the condition is based, is to deprive the subject of the benefit of a large body of refined experimental and clinical study. In the same way allergic study cannot afford to overlook the clinical importance of the precipitating factors which in themselves may have no bearing on antigen-antibody relationships.

\section{Acknowledgments}

My thanks are due to Professor G. Payling Wright for his generous advice and criticism, and to Dr. A. Mohun for reading this paper. The author is in receipt of a grant from the Medical Research Council.

\section{BIBLIOGRAPHY}

ABELL, R. G., and SCHENCK, H. P. (1938), f. Immunol., 34, 195. ARONSON, J. D. (1931), f. exp. Med., 54, 387.

ARTHUS, M. (1903), C.R. Soc. Biol., 55, 817.

BAILLY, M. D. (1950), 7. Immunol., 64, 245.

BALDRIDGE, C. D., and KLIGMAN A. M. (1951), Amer. Rev. Tuberc., 63, 674 .

BARBER, M., and DELAUNAY, A. (1952), Postgrad. med. F., 28, $35 \mathrm{I}$.

BENACERRAF, B., and KABAT, E. A. (1949), F. Immunol., 62, $97,517$.

BLOCH, B., and STEINER-WOURLISCH, A. (1926), Arch. f. Dermat., 152, 283.

BURKY, E. L. (1934) F. Allergy, 5, 466.

CAMPBELL, C. A. (1945), Canad. Med. Assocn. F., 52, 280.

CAVELTI, P. A. (1945), Proc. Soc. exp. Biol., N.Y., 60, 379.

CAVElTi, P. A., and CAVELTI, E. S. (1945), Arch. Path., 40, $158,163$.

CHASE, M. W. (1941), f. exp. Med. 73, 711.

CHASE, M. W. (1942), Proc. Soc. exp. Biol., N.Y., 49, 688.

CHASE, M. W. (1945), Ibid., 59, 134.

CHASE, M. W. (1946), Ibid., 6r, 257.

CHASE, M. W. (1949), Soc. Amer. Bacteriologists, 1949 Meeting

CHASE, M. W. (195I), Fed. Proc., 10, 404.

CHASE, M. W. (1952), Amer. F. Med., 13, 357.

CODE, C. F. (1952), Physiol. Rev., 32, 47.

COOKE, R. A., BARNARD, J. H., HEBALD, S., and STULL, A. (1935), F. exp. Med., 62, 733 .

CORNFORTH, J. W., and LONG, D. A. (1952), Lancet, i, 950.

COULSON, E. J., and STEVENS, H. (I949), F. Immunol., 6r, I, II, II 19 . 
COURTNEY, R. H. (1929), Amer. F. Ophth., 12, 20.

CRUICKSHANK, C. N. D. (1951), Nature, 168, 206.

CUMMINGS, M. M., and HUDGINS, P. C. (1952), f. Immunol., 69, 331 .

DALE, H. (1948), Brit. med. F., ii, $28 \mathrm{r}$.

D'ARCY HART, P., LONG, D. A., REES, R. J. W. (1952), Ibid., i, 680 .

DEAN, H. R., and WEBB, R. A. (r924), f. Path. and Bact., 27, 65.

DERICK, C. L., and SWIFT, H. F. (1929), f. exp. Med., 49, 615.

DIENES, L., and SCHOENHEIT, E. W. (I929), Amer. Rev. Tuberc., 20, 92.

DIENES, L., and SIMON, F, A. (I935), f. Immunol., 28, $32 \mathrm{r}$.

DOERR, R., and BERGER, M. (1922), Zeit.f. Hyg., 96, $19 \mathrm{I}$.

DOUGHERTY, T. F., and SCHNEEBELI, C. F. (1950), Proc. Soc. exp. Biol., N. Y., 75, 854 .

EBERT, R. H., and WISSLER, R. W. (I95I), F. Lab. and Clin. Med., 38, 497.

EBERT, R. H. (1952), Amer. Rev. Tuberc., 65, 64.

EISEN, H. N., ORRIS, L., and BELMAN, S. (1952), f. exp. Med., $95,473$.

é SILVA, R. (1950), Ann. N.Y. Acad. Sciences, 50, 145.

EVERETT, E. T., LIVINGOOD, C. S., POMERAT, C. M., and FUNAN, H. V. (1952), f. Invest. Dermatol., 18, 193.

FABRIZIO, A. M. (1952), Amer. Rev. Tuberc., 65, 250.

FAVOUR, C. B. (1947), Proc. Soc. exp. Biol., N.Y., 65, 269.

FISCHEL, E. E., and KABAT, E. A. (1947), F. Immunol., 55, 337.

FISHER, N., HARINGTON, C., and LONG, D. A. (195I), Lancet, ii, 522.

FRANCIS, T., JUN., and TILLETT, W. S. (1931), f. exp. Med., $54,587$.

GELL, P. G. H., HARINGTON, C. R., and RIVERS, R. P. (I946), Brit. Э. exp. Path., 27, 267.

GELL, P. G. H., and HINDE, I. T. (195I), Ibid., 32, 516 .

GILBERT, A. J. (1938), F. Pharm. and exp. Therap., 62, 228.

GLYNN, L. E., and HOLBORROW, E. J. (1952), Lancet, ii, 449.

GOODMAN, E. L. (i935), Arch. Ophth., 14, 90.

HALPERN, B. N., MAURIC, G., HOLTZER, A., and BRIOT, M. (195I), Acta. allerg. Kbh., 4, 207.

HARLEY, D. (1937), F. Path. and Bact., 44, 589.

HAWN, C. VAN Z., and JANEWAY, C. H. (1947), f. exp. Med., 85,57 r.

HECHT, R., SUZLBERGER, M. B., and WEIL, H. (1943), Ibid., 78, 59 .

HEILMAN, D. H., FELDMAN, W. H., and MANN P. C. (1944), Amer, Rev. Tuberc., 50, 334.

HEKTOEN, L. (1932), Arch. Path., 14, 837

HUMPHREY, J. H. (1948), F. Path. and Bact., 60, 21 r.

HUMPHREY, J. H. (1951), Brit. F. exp. Path., 32, 274.

HYDE-SALTER, H. H. (1868), 'Asthma,' Churchill, London.

KABAT, E. A., WOLF, A., and BEZER, A. E. (1946), Science, 104, 362 .

KABAT, E. A., WOLF, A., and BEZER, A. E. (1947), f. exp. Med., 85,117 .

KABAT, E. A., COFFIN, G. S., and SMITH, D. J. (1947), $\mathcal{f}$. Immunol., 62, 97, 517 .

KABAT, E. A. (1952), Amer. F. Med., 13, 352.

KIRCHHEIMER, W. F. HESS, A. R., and SPEARS, R. G. (1951), Amer. Rev. Tuberc., 64, 5 I6.

KLEMPERER, P. (1947), 'Allergy,' R. A. Cooke, Saunders, Phil., p. 76.

KLINGE, F. (1929), 'Allergie,' W. Berger and R. Hansen, Thieme, Leipzig.

LANDSTEINER, K., and CHASE, M. W. (1940), Proc. 3rd Internat. Congress Microbiol., 4, 772.

LANDSTEINER, K., and CHASE, M. W. (1942), Proc. Soc. exp. Biol., N.Y., 49, 688.

LANDSTEINER, K. (1945), 'The Specificity of Serological Reactions,' Harvard Univ. Press, Camb., Mass.

LAPORTE, R. (1934), Ann. Inst. Pasteur, 53, 598.

LAWRENCE, H. S. (1949), Proc. Soc. exp. Biol., N.Y., 71, 516.

LAWRENCE, H. S. (I952), F. Immunol., 68, 159.

LENNOX, B., DEMPSTER, W. J., and BOAG J. W. (1952), Brit. F. exp. Path., 33, 380.

LONG, D. A., MILES, A. A., and PERRY, W. L. M. (195r), Lancet, $\mathrm{i}, 1085$.

LONG, D. A., MILES, A. A., and PERRY, W. L. M. (1951), Ibid., ii, 902 .

LOVELESS, M. H. (1940), F. Immunol., 38, 25.

LOVELESS, M. H. (I941), Ibid., 4I, I5.

LOVELESS, M. H. (1942), Ibid., 44, I.

LOVELESS, M. H. (1943), Ibid., 47, 165 .

LUCIC, H. (1939), Proc. Soc. exp. Biol., 40, 273.
MACKENZIE, G. M., and LEAKE, W. H. (I92I), f. exp. Med., 33, 601 .

MARRACK, J. R. (195I), Internat. Arch. Allergy., 2, 264.

MCINTOSH F. C., and PATON, W. D. M. (1949), F. Physiol., 109, 190.

MCMASTER, P. D., and KRUSE, H. (195 I), F. exp. Med., $94,323$. MAHLMAN, J., and SEEGAL, B. C. (1934), $\mathcal{F}$. Immunol., 26, 1.

MEYER, K., and LOEWENTHAL, H. (1927), $Z$. $f$. Immunitatsforsch. $u$. exp. Therap., 54, 420.

MICHAEL, M., and WHORTON, C. M. (1951), Proc. Soc. exp. Biol., N.Y., 76, 754.

MILLER, J. M., and FAVOUR, C. B. (195I), F. $\operatorname{exp.~Med.,~93,~I.~}$ MOEN, J. K., and SWIFT, H. F. (1936), Ibid., 64, 339, 943.

MOEN, J. K. (1936), F. exp. Med. 64, 355.

MORE, R. H., and MACLEAN, C. R. (1949), Amer. F. Path., 25, 4I3.

MORGAN, I. M. (1946), F. Bact., 5I, 6 r4.

MORGAN I. M. (1947), f. exp. Med., 85, 131 .

MOTE, J. R., and JONES, T. D. (1936), F. Immunol., 30, 149.

OBERMAYER, F, and PICK, E. P. (1906), Wien. Klin. Wchnschr., $19,327$.

OPIE, E. L. (I924), f. Immunol., 9, 23I, 247, 255, 259.

OTTO, R. (1907), Muenchen med. Wchnschr., 54, 1665.

PORTIER, P., and RICHET, C. (1902), Compt. Rend. Soc. de Biol., 54, 170.

PRAUSNITZ, C., and KUESTNER, H. (1921), Zentralbl. $f$. Bakt. (Orig.), 86, 160 .

RAFFEL, S. (1946), Amer. Rev. Tuberc., 54, 564.

RAFFEL, S. (1948), f. Infect. Dis., 32, 267.

RAFFEL, S., and FORNEY, J. E. (1948), Ғ. exp. Med., 88, 485.

RAFFEL, S., ARNAUD, L. E., DUKES, C. D., and HUANG J. S. (1949), Ibid., 90, 53.

RAJKA, E., and HEGYI, E. (1950), Internat. Arch. Allergy, 1, 243.

REDDIN, L. (1949), Annals N.Y. Acad. Sciences, 50, 692.

RICH, A. R., and LEWIS, M. R. (1932), Bull. Fohns Hopkins Hosp., 50, II 5 .

RICH A. R., and FOLLIS, R. H., JUN. (1940), Ibid., 66, 106.

RICH A. R., and GREGORY, J. E. (1943), Ibid., 72, 65.

RICH, A. R., and GREGORY, J. E. (1943), Ibid., 73, 239.

RICHET, C. (1907), Ann. Inst. Pasteur, 21, 497.

ROSA, L. M., and MACDOWALL, R. J. S. (195I), Acta. allerg. Kbh., 4, 293.

SARBER, R. W. (1948), Amer. Rev. Tuberc., 57, 504.

SCHILD, H. O. HAWKINS, D. F., MONGAR, J. L., and HERXHEIMER, H. (195I), Lancet, ii, 376 .

SEEGAL, D., and SEEGAL, B. C. (193I), f. exp. Med., 54, 249, 265.

SEEGAL, B. C., and SEEGAL, D. (1933), F. Immunol., 25, 22 I.

SEEGAL, B. C., and WILCOX, H. B., Jun. (1940), Arch. Path., 30, 416 .

SEEGAL, B. C. (1952), Amer. F. Med., 13, 354.

SEIBERT, F. B., and MORLEY, N. (I933), f. Immunol., 24, I49.

SOLLMAN, T., and GILBERT, A. J. (1937), f. Pharm. and exp. Therap., 61, 272.

STETSON, C. A. (1951), Ұ. exp. Med., 94, 347.

SULZBERGER, M. B. (1940), 'Dermatologic Allergy,' Thomas, Springfield.

THOMAS, L., CURNEN, E. C., MIRICK, G. S., ZEIGLER, J. E., JUN:, and HORSFALl, F. L., JUN. (1943), Proc. Soc. exp. Biol., N.Y., 52, 121 .

URBACH, E., and GOTTLIEB, P. M. (1946), 'Allergy,' Grune and Stratton, New York.

VERHOEFF, F. H., and LEMOINE, A. N. (1922), Amer. $\boldsymbol{f}$. Ophth., 5, 700.

v. PIRQUET, C., and SCHICK, B. (I905), 'Serum Sickness,' Williams \& Williams, Baltimore, $95 \mathrm{I}$.

v. PIRQUET C. (1906), Muenchen med. Wchnschr., 30, 1457.

WEBB, R. A. (1924), F. Path. and Bact., 27, 79.

WESSLEN, T. (1952), Acta. Tuberc. Scand., 26, 38, 175.

WESSLEN, T. (1952), Acta. Dermato-Venereol., 32, 195.

WHITFIELD, A. (1922), Brit. F. Dermat., 34, 331.

WILCOX, H. B., JUN., and ANDRUS, E. C. (1938), f. exp. Med. 67, 169.

WITTICH, F. W. (1949), ' Progress in Allergy,' P. Kallos, Karger, Basel.

WOODS, S. (1940), 'Modern Trends in Ophthalmology,' Butterworth \& Co., London.

WRIGHT, G. P., and HOPKINS, S. J. (194I), F. Path. and Bact., WRIGHT, G. P., and LAWS, J. O. (1952), Brit. F. exp. Path., ZOUTENDYK, A., and GEAR, J. H. S. (1950), Brit, med. F., ii, 1175. 